\title{
Life Satisfaction among Farmers in Paddy Granaries in Malaysia
}

\author{
Rika Terano $^{1} \&$ Zainalabidin Mohamed $^{1}$ \\ ${ }^{1}$ Department of Agribusiness and Information Systems, Faculty of Agriculture, Universiti Putra Malaysia, UPM \\ Serdang, Selangor DE, Malaysia \\ Correspondence: Rika Terano, Department of Agribusiness and Information Systems, Faculty of Agriculture, \\ Universiti Putra Malaysia, 43400 UPM Serdang, Selangor DE, Malaysia. Tel: 60-10-789-5706. E-mail: \\ rikate@gmail.com
}

\author{
Received: September 17, 2013 Accepted: November 20, 2013 Online Published: December 29, 2013 \\ doi:10.5539/ass.v10n2p229 \\ URL: http://dx.doi.org/10.5539/ass.v10n2p229
}

\begin{abstract}
The industrial policy that was undertaken by the Malaysian government has spurred economic development and prosperity for the last 3 decades. Nevertheless the economic development has been heavily concentrated on the west coast of Peninsular Malaysia, thus causing income disparity between urban and rural areas. The government has published a series of reports on Malaysian Quality of Life (QoL) since 2002. It measured QoL among Malaysian people narrowly from the material aspects of QoL. However, it is also very important to approach people's QoL not only from the material aspects but also from non-material aspect of QoL including happiness, satisfaction and desire and how they generally feel about their life. It would provide distinctive indicators among Malaysian people. This paper aims to approach life satisfaction weather people are satisfied with their life or not especially from both material and non-material aspects of QoL among Malaysian people living in two granary areas of Penang and Kelantan. A total of 80 respondents were interviewed by structured questionnaires, and binary logistic regression was used to determine the influential socio-demographic factors and important dimension of the QoL on life satisfaction. The result indicates that age, family size and four dimensions of QoL such as community, residential condition, economic level, and family/partner were important factors in influencing on life satisfaction. Especially, QoL in terms of community dimension was the most influential factor on life satisfaction.
\end{abstract}

Keywords: life satisfaction, non-material aspect of QoL, granaries area, binary logistic regression, QoL

\section{Introduction}

Economic growth has reduced poverty and has improved the living standards among the Malaysians (World Bank, 2009). This has taken place since 1980s when multinational companies began investing in Malaysia by building factories on the West coast of Peninsula Malaysia. It has absorbed a lot of people from rural areas as the labour force and settled them in the designated industrial parks. Since job opportunities in factories have provided Malaysian people with cash wage, it has led to the development of the monetary economy in the rural area. However, income growth has been strong only for the top $20 \%$ of Malaysian income earners. The bottom $40 \%$ of households have experienced the slowest growth of average income, earning less than RM1,500 per month in 2008 (National Economic Advisory Council (NEAC), 2010). Since reducing poverty from rural sector was a predominant key issue in Malaysia in a series of Malaysia Plans, people's living standards in rural sector were addressed as an important perspective for approaching rural development (Hashim, 1998; Khan, 2002).

Among Southeast Asian countries, the Malaysian government started to use the term "quality of life" quite early, as noted in the Malaysian Plans. The Malaysian Quality of Life (QoL) report, defined it as encompassing personal advancement, a healthy lifestyle, access and freedom to pursue knowledge and attainment of a living standard which surpasses the fulfillment of the basic and psychological needs of the individuals to achieve a level of social well-being compatible with the nation's aspirations (MQOL, 2002). It captured the Malaysian's QoL by measurable material perspective from mainly 11 perspectives including income/distribution, working life, transport/communication, health, education, housing, environment, family life, social participation, public safety, culture and leisure. They also indicated that living standards in Malaysia have dramatically improved except from the point of environment and public safety which were caused by the rapid urbanization (MQOL, 2004).

Since 1980s, the manufacturing sector has been invested in by multinational and domestic companies, which has 
led to more employment opportunities in the manufacturing sector. As indicated earlier the phenomena provided chances to earn cash income for Malaysian people. Since most of the industrial parks are located on the West coast of Malaysia's so called urban area, Malaysia holds the issue of regional disparity between urban and rural areas. Thus it is imperative to approach life satisfaction in terms of material and non-material aspects of QoL among urban and rural people. In order to reveal people's life satisfaction in the granary areas, which are in the midst of an economic growth and development, this study intends to underline determinants specifically influencing the paddy farmers' life satisfaction including given the job opportunities which have been created by the economic development. This research field which is mostly developed in phycology or medical health matters in Malaysia is able to provide a way to deal with improving the QoL in Malaysia from people's perspective. In this study we attempt to interview farmers about their life satisfaction and QoL in two granary areas of Sebrang Perai, Penang and KADA, Kelantan in which Seberang Perai is located in the industrial park of Penang while KADA is not located in an industrial zone of development. Specifically, the questionnaire covered farmer's QoL from the perspective of community, residential condition, satisfaction with income, and partner/family life.

Quality of Life (QoL) has been a focus of Malaysian researchers and policy-makers for an ultimate use from a different perspective. It consisted of not only material QoL but also wider measures of social-economic QoL including non-monetary indices. This is because materials for measuring QoL alone cannot explain a broader concept and the objective is to measure the extent to which human needs are actually being met (Costanza, Hart, Posner, \& Talberth, 2009), which can be defined and measured as both satisfaction with life in general (uni-dimensional) and satisfaction with different aspects, or domains of life (multi-dimensional) (Galloway, 2005). In order to indicate people's QoL, multi-dimensional QoL measurement through psychological, social and physical functioning was found to be more realistic. In 2005, Economic Intelligent Unit (EIU) of Malaysia (The Economists, 2005) has analyzed across 74 countries in explaining life satisfaction outcomes regarding the effects of subjective well-being indicators. Main determinants of subjective well-being were listed as follows: health, political stability and security, family life, community life, climate and geography, job security, political freedom and gender equality.

Due to the economic growth in ASEAN countries, QoL, has been one issue of concerns. Recently, there are some studies regarding QoL in Southeast Asian countries. Kuan and Jiuan (2011) indicate that demographic and non-demographic factors contributed differently towards the general QoL of people in ASEAN. The indicators of subjective QoL (happiness, enjoyment, and achievement) were used as dependent variables. The demographic factors such as age, gender, education, and income played significant roles in explaining the people's QoL in ASEAN either singly or in combination. In case of Malaysia, gender was the only significant variables where males were happier compared to their female counterparts. Income had a negative impact on achievement for Malaysians, the Philippinos, Singaporeans, and the Thais and a negative impact on enjoyment for Indonesians. Generally, demographic factors seem to play a lesser role in impacting the happiness for people in the ASEAN.

In Malaysia, the major issues of QoL, it is more from physiological and health perspective. There was an attempt at improving QoL among patients. The term used was "Spiritual Quality of Life (SPQoL)" in which physical, social, and other domains are included in mental care by nurses. Plante and Sherman (2001) pointed out that there is a connection between spiritual or religious engagement and well-being among cancer patients in decreasing the intensity of pain. There are various studies concerning the relationship between health and religious beliefs, or well-being and emotions (Koenig \& Brooks, 2002; Kahneman, Diener, \& Schwarz, 2003). There are some studies concerning the relationship between personality and subjective well-being among Malaysians. Muhamad and Jaafar (2009) clarified the association between demographics and mental health status of young adults in Malaysian universities. Md Nordin, Abu Talib and Yaacob (2009) examined the relationship between personality and loneliness on mental health among undergraduates in Malaysia. A total of $65.6 \%$ of respondents exhibited healthy mental health and $34.4 \%$ showed indications of mental health problems. Loneliness was the most significant predictor in explaining mental health followed by neuroticism and extraversion personality. Momtaz, Ibrahim, Hamid and Yahaya (2011) showed that the old and elderly women, unmarried, and the poor elderly people are at risk of experiencing low psychological QoL. QoL among youth or young adults is often related to mental health from physiological studies.

Additionally, there is a research conducted by Cheah and Tang (2011) regarding the role of socio-demographic factors on self-rated happiness. They examined main determinants on individual's level of happiness in Penang by considering actual criteria of age, gender, income, education and race. Based on the findings, being married and Malay are associated with higher probability of feeling very happy or happy. Nevertheless, individuals who suffer from chronic diseases are more likely to have unhappy or very unhappy feelings. The rest of the factors 
such as income, education, age, gender, and employment status are found to have insignificant effects on happiness. This is while individual's health background, ethnic background and marital status show significant impacts on happiness.

\section{Material and Method}

\subsection{Sample and Questionnaire}

In this study, 80 respondents were interviewed by using a structured questionnaire to collect information related to QoL. Household heads from 2 different granary areas were interviewed relating to rice farming. Surveys were conducted in Kampung Permatan Tinggi Bakar Bata, Penang and Kampung Hutan Chengal, Kelantan on the both coastal areas of West and East coast of Peninsular Malaysia respectively. The questionnaire contained respondent's socio-demographic characteristics such as age, income, number of family member, location in the first section and dimensions of QoL in the second section. The QoL dimension questions focus on items such as community, residential condition, economic level, partner and family. The Likert scale of 1 to 5 is being used to indicate the satisfaction level for the questions related to QoL, where 1 is strongly dissatisfied and 5 is strongly satisfied for the statement that is being asked.

\subsection{Research Hypothesis}

With the economic growth in ASEAN countries, QoL, has been one issue of concerns. Based on previous studies regarding QoL in Southeast Asian countries as discussed earlier, the following hypothesis concerned with farmer's life satisfaction is being formulated as follows:

Hypothesis: There is no relationship between life satisfaction, socio-demographic factors such as age, income, number of family member, location, and dimension of the QoL such as community, residential condition, economic level, partner and family.

\subsection{Method of Analysis}

Firstly, descriptive analysis was conducted to show the respondent's socio-demographic variables. Secondly, binary logistic model was used to determine influential factors on life satisfaction. In this model, all of the explanatory variables consist of the value 0 or 1 , to calculate the categorical explanatory variables of life satisfaction including demographic profile and dimensions of QoL (Table1). The equation of this model is shown as follows:

$$
\text { Logit }(Y)=\text { natural } \log (\text { odds })=\ln (\pi / 1-\pi)=\alpha+\beta \mathrm{x}
$$

Through the dependent variable, $Y$ represents the life satisfaction which has two categories of 'being satisfied with life' coded as one and 'not satisfied with life' coded as zero. The variables $\mathrm{x}_{\mathrm{i}}$ represents the different demographic variables including residential location, age, monthly household income and number of family members. Also it includes dimensions of QoL. The average satisfaction is calculated by taking the average score of the Likert scale for each of the statements respectively.

The binary logistic model can be stated as follows:

$$
\begin{gathered}
\ln (\pi / 1-\pi)=\beta_{0}+\beta_{1} x_{\text {age of household head }}+\beta_{2} x_{\text {monthly household income }}+\beta_{3} x_{\text {number of family member }}+\beta_{4} x_{\text {residential location }}+\beta_{5} x_{\text {dimension of QoL }} \\
\text { (community) }+\beta_{6} x_{\text {dimension of QoL (residence condition) }}+\beta_{5} x_{\text {dimension of QoL (economic level) }}+\beta_{6} x_{\text {dimension of QoL(partner and family) }}+\mathrm{e}_{i}
\end{gathered}
$$

Table 1. Explanatory variables to determine life satisfaction

\begin{tabular}{lll}
\hline Explanatory variables & Coding systems \\
\hline Demographic Profile & 0 & Below 55 years old \\
Age of household head & 1 & Above 55 years old \\
& 0 & Below RM3,000 \\
Monthly household income & 1 & Above RM3,000 \\
& 0 & Below 5 persons \\
Number of family member & 1 & Above 5 persons \\
& 0 & East coast: Kelantan \\
Location & 1 & West coast: Penang \\
& & \\
Dimension of QoL & 0 & Below average satisfaction \\
Community & & \\
\hline
\end{tabular}




\begin{tabular}{lll}
\hline Explanatory variables & \multicolumn{2}{l}{ Coding systems } \\
\hline \multirow{2}{*}{ Residential condition } & 1 & Above average satisfaction \\
& 0 & Below average satisfaction \\
Economic level & 1 & Above average satisfaction \\
& 0 & Below average satisfaction \\
Partner and family & 1 & Above average satisfaction \\
& 0 & Below average satisfaction \\
Source: Own survey 2012 & 1 & Above average satisfaction \\
\hline
\end{tabular}

\section{Results and Discussion}

\subsection{Descriptive Analysis}

Table 2 shows the respondents demographic profile in the two villages. Approximately fifty two percent (52.5) of the respondents were from Penang and 47.5 percent were from Kelantan. In this study, all of the respondents were household heads and the majority was male at 82.5 percent. Due to the increasing age of farmers, more than 60.0 per cent of respondents were over 55 years old, while only 40.0 percent were below 55 . The education level of respondents was categorized into three groups; 50.0 percent of respondents completed primary school, 20 percent did not complete or never went to primary school, and 30.0 percent completed secondary school. There was 30 percent of the respondents who had household income below RM 2,000 per month including both on-farm and off-farm incomes. More than half respondents' household income was between RM 2001-4,000 per month. Respondents' family size was relatively large and the majority had ' $4-5$ ' and ' $6-7$ ' family members living in their households.

Table 2. Demographic profile of respondents $(\mathrm{N}=80)$

\begin{tabular}{lll}
\hline Characteristics & No. & Percentage \\
\hline Gender & 66 & 82.5 \\
Male & 14 & 17.5 \\
Female & 32 & 40.0 \\
Age & 11 & 13.8 \\
Below 55 & 37 & 46.2 \\
$55-60$ & & \\
Above 60 & 40 & 50.0 \\
Education level & 24 & 30.0 \\
No schooling/primary school & 16 & 20.0 \\
Secondary school & & \\
University & 42 & 52.5 \\
Location & 38 & 47.5 \\
Penang & & \\
Kelantan & 30 & 37.5 \\
Monthly household income & 12 & 15.0 \\
Below 2,000 & 12 & 15.0 \\
2,000-2,999 & 26 & 32.5 \\
3,000-4,000 & & \\
Above 4,000 & & \\
Family size & 17 & 21.3 \\
1-3 & 26 & 32.5 \\
4-5 & 25 & 31.3 \\
A-7 & 12 & 15.0 \\
Source: Own survey 2012 & & \\
\hline Not: & & \\
\hline
\end{tabular}

Note: *Including not completed primary school 


\subsection{Respondents' Dimensions of Qol}

Table 3 shows the mean score and distribution of Likert scale score in percentage using 5 points scales (1 to 5). The result indicates that respondents are relatively satisfied with their life from the dimension of QoL such as community, residential condition, economic level, and family/partner. The distribution of each question has skewed more on well satisfied score such as 4 and 5 on Likert scale score. We can see that respondents had a positive perception towards QoL.

Table 3. Respondents' respond to their dimensions of QoL living in granary community in two villages

\begin{tabular}{|c|c|c|c|c|c|c|}
\hline \multirow{2}{*}{ Statement } & \multicolumn{5}{|c|}{ Liker scale score (percentage) } & \multirow{2}{*}{ Mean } \\
\hline & 1 & 2 & 3 & 4 & 5 & \\
\hline \multicolumn{7}{|l|}{ Community } \\
\hline Are you happy with your neighbors? & 0.00 & 2.50 & 3.75 & 10.00 & 83.75 & 4.75 \\
\hline $\begin{array}{l}\text { Are you satisfied with your network of neighbors } \\
\text { and relatives? }\end{array}$ & 0.00 & 1.25 & 2.50 & 11.25 & 65.00 & 4.80 \\
\hline \multicolumn{7}{|l|}{ Residential condition } \\
\hline Are you satisfied with your house? & 0.00 & 3.75 & 1.25 & 8.75 & 86.25 & 4.78 \\
\hline \multicolumn{7}{|l|}{ Economic level } \\
\hline Are you satisfied with your current income? & 1.25 & 12.50 & 1.25 & 32.50 & 52.50 & 4.23 \\
\hline Are you satisfied with your family's income? & 1.25 & 1.25 & 18.75 & 21.25 & 57.50 & 4.33 \\
\hline \multicolumn{7}{|l|}{ Family and partner } \\
\hline Are you happy with your partner? & 0.00 & 0.00 & 1.25 & 7.50 & 91.25 & 4.90 \\
\hline Are you happy in your family? & 1.25 & 0.00 & 15.00 & 10.00 & 73.75 & 4.56 \\
\hline \multicolumn{7}{|l|}{ Source: Own survey 2012} \\
\hline Note: 1 = Strongly dis-satisfied; 5 Strongly satisfied & & & & & & \\
\hline
\end{tabular}

\subsection{Binary Logistic Regression}

A binary logistic model was used to determine main factors influencing life satisfaction among paddy farmers. In the analysis, the overall classification accuracy was 81.2 per cent. This overall predictive accuracy of the discriminant function is called the 'hit ratio'. The hit ratios provided an adequate level of predictive accuracy. There are two statistics used to determine whether the model is significant: the-2 log likelihood and chi-square (Rosenfield \& Penrod, 2009). The Hosmer-Lemeshow test is a commonly used test for assessing the goodness of fit model and allows for any number of explanatory variables (Bewick, Cheek, \& Ball, 2005). The results $\left(\chi^{2}=\right.$ $12.788,8$ degrees of freedom, $\mathrm{P}=0.119$ ) indicate that the goodness of fit is satisfactory which suggests that the numbers of farmers between 'satisfied with life' and 'not satisfied with life are not significantly different from those predicted by the model. The Cox \& Snell and the Nagelkerke $\mathrm{R}^{2}$ are 0.299 and 0.405 , respectively. In social science, low R-square in regression equation are not uncommon (Wooldridge, 2012). Above $15 \%$ of explained variance is still acceptable in the context of social science result (Giroud, 2003).

The coefficients estimated from a binary logistic regression model can be interpreted directly in the context of a one unit change in the independent variable (Piquero \& Weisburd, 2010). Wald estimates give the "importance" of the contribution of each variable in the model and the higher the value, the more "important" it is (Chan, 2004). Based on Wald, community dimension was the most important at 9.596 followed by dimension of economic level at 3.527. The estimated coefficient and statistical significance levels for the logistic regression are shown in Table 4. The result of the binary logistic regression also indicates that four dimensions of QoL were statistically significant with positive signs.

Among the statistically significant variables in the socio-demographic characteristics was age of household head which is an important factor to determine life satisfaction with a negative sign. This finding reveals that younger farmers are more satisfied with their life than elder farmers. In case of the family size, it was statistically significant at $10 \%$ with a negative sign. It indicates that respondents with smaller size were more satisfied with their lives. It was reported in UK that presence of more children entails pressure on income, time and opportunities and emerges greater dissatisfaction among young parents (Avramov, 2002). The dimensions of community, residential condition, economic level, and family/partner, were the most important determinants and statistically significant at $1 \%$ level with a positive sign. It shows that respondents who were satisfied with their community are 11.319 times more satisfied than that of respondents who were not satisfied with the community. 
Also among respondents who were satisfied with their partner and family, the likelihood of satisfaction increases 7.258 times more than the respondents who were not satisfied with their partner/family.

Table 4. Determinants on measurement of life satisfaction

\begin{tabular}{|c|c|c|c|c|c|}
\hline Variable & Estimated Coefficient & Standard Error & Wald & $\overline{\operatorname{Exp}(B)}$ & \\
\hline Constant & -2.654 & -2.654 & 3.973 & 0.700 & $* *$ \\
\hline \multicolumn{6}{|l|}{ Socio demographic } \\
\hline Age of household head & -1.545 & 0.661 & 0.497 & 0.213 & \multirow[t]{2}{*}{$* *$} \\
\hline Monthly household income & -0.459 & 0.651 & 0.497 & 0.632 & \\
\hline Number of family & -1.159 & 0.642 & 3.252 & 0.314 & \multirow[t]{2}{*}{$*$} \\
\hline Location & -0.825 & 0.658 & 3.252 & 0.438 & \\
\hline \multicolumn{6}{|l|}{ Dimensions of QoL } \\
\hline Community & 2.426 & 0.783 & 9.596 & 11.319 & $* * *$ \\
\hline Residential condition & 1.218 & 0.652 & 3.485 & 3.380 & $*$ \\
\hline Economic level & 1.118 & 1.088 & 3.527 & 3.057 & $*$ \\
\hline Family/partner & 1.982 & 1.088 & 3.317 & 7.258 & $*$ \\
\hline-2 Log likelihood & 78.424 & \multicolumn{2}{|c|}{ Nagelkerke square } & \multicolumn{2}{|l|}{0.405} \\
\hline Cox \& Snell R square & 0.299 & \multicolumn{2}{|c|}{ Hosmer and Lemeshow Test } & \multicolumn{2}{|l|}{12.788} \\
\hline Source: Own survey 2012 & & & & & \\
\hline
\end{tabular}

Note:*** denotes $1 \%$ significance; $* *$ denotes $5 \%$ significance; $*$ denotes $10 \%$ significance

\section{Conclusion}

Descriptive analysis and binary logistic model were used to determine main factors influencing paddy farmers' life satisfaction among paddy farmers. The survey was conducted in two rice growing villages; however it was found that there was no clear difference on life satisfaction between the two villages. In terms of locational factor, the areas where the surveys were conducted were considered within the rural sector and there was no apparent difference between the areas on East and West coast of the Peninsula Malaysia although one is located in industrialized zone. Thus monetary gain or value or the opportunity to earn income from industrial development is not the main determinant of the life satisfaction but dimension of QoL, especially community dimension and family/partner dimension are the main concerns. In the case of socio-demographic factors, age of household head is an important factor followed by the number of family members. This finding revealed that younger farmers were more satisfied with their lives than the older ones. This can be interpreted in the way that younger farmers as household heads were more satisfied with their lives at an early stage of their family plan because a smaller number of family members contributed to greater satisfaction in their lives among the socio-demographic characteristics. These finding was similar to a study conducted by Gough and MacGregor (2007) that younger people are more satisfied with their lives because they have higher satisfaction with the economic, job, personal domains and community domains of life which all in turn contribute to life satisfaction (Gough \& MacGregor, 2007).

Among four dimension of QoL, community dimension where farmers belong to is considered to as the most important factor with life satisfaction. Malay kampong where they live in has traditionally had multiple functions for mutual cooperation, so called "Gotong Royong" based on blood relation and territorial bonding. Ever since technologies have become widespread in paddy farming process, the community role is not largely limited to joint operation in transplanting and harvesting, which plays more important on people's lives but often related to Islamic religious activities. Most studies find a positive association between religious involvement and individuals' QoL (Lim \& Putnam, 2010). Thus it can be assumed that being a member of Malay community secures and befits social protection if you are involved in religious ceremonies and rites, followed by the community and other dimensions of QoL. Even though money economy had deepened inside the rural sector, household income was not directly related to people's QoL. The dimensions of economic level and residential condition are more related to their dimensions of QoL than the actual amount of income they earn.

\section{Acknowledgement}

This research is funded by Universiti Putra Malaysia (UPM) under the Research University Grant Scheme Initiative 2 (RUGS-2). The authors would like to thanks UPM for sponsoring this research from September 2012-July 2014. 


\section{References}

Avramov, D. (2002). People, Demography and Social Exclusion. Council of Europe, 304.

Bewick, V., Cheek, L., \& Ball, J. (2005). Review Statistics review 14: Logistic regression. Critical Care, 9(1). http://dx.doi.org/10.1186/cc3045

Chan, Y. H. (2004). Biostatistics 202: Logistic regression analysis. Singapore Med. J., 45(4), 14.

Cheah, Y. K., \& Tang, C. F. (2011). The role of socio-demographic factors on self-rated happiness: The case of Malaysia. Munich Personal RePEc Archive, (29419), 1-11.

Costanza, R., Hart, M., Posner, S., \& Talberth, J. (2009). Beyond GDP: The need for new measures of progress. The pardee paper No. 4, The Frederick S. Pardee Center for the study of the Lnger-Range Future, Boston University.

Galloway, S. (2006). Quality of life and well-being: Measuring the benefits of culture and sport: Literature review and think piece. Centre for Cultural Policy Research University of Glasgow, Scottish Executive, 160.

Giroud, A. (2003). Transnational corporations, technology, and economic development: Backward linkages and knowledge transfer in South East Asia. Edward Elgar Publishing, 358.

Gough, I., \& McGregor, J. A. (2007). Wellbeing in developing countries: From theory to research. Cambridge University Press. http://dx.doi.org/10.1017/CBO9780511488986

Hashim, S. M. (1998). Income inequality and poverty in Malaysia. London: Rowman and Littlefield.

Kahneman, D., Diener, E., \& Schwarz, N. (2003). Well-being: The foundations of hedonic psychology. New York: Russell Sage Foundation.

Khan, M. H. (2002). When Is Economic Growth Pro-Poor? Experiences in Malaysia and Pakistan (EPub). International monetary fund.

Koenig, H. G., \& Brooks, R. G. (2002). Religion, health, and aging: Implications for practice and public policy. Public Policy and Aging Report, 12(4), 13-19.

Kuan, T. S., \& Jiuan, T. S. (2011). Subjective Wellbeing in ASEAN: A Cross-country study. Japanese journal of political science, 12(3), 359-373. Cambridge University Press. http://dx.doi.org/10.1017/S1468109911000168

Lim, C., \& Putnam, R. D. (2010). Religion, social networks, and life satisfaction. American Sociological Review, 75(6), 914-933. http://dx.doi.org/10.1177/0003122410386686

Malaysia, Economic Planning Unit. (2002). Malaysian quality of life. Kuala Lumpur.

Malaysia, Economic Planning Unit. (2004). Malaysian quality of life. Kuala Lumpur.

Md Nordin et al. (2009). Personality, loneliness and mental health among undergraduates at Malaysian Universities. European journal of scientific research, 36(2), 285-298.

Momtaz, Y. A., Ibrahim, R., Hamid, T. A., \& Yahaya, N. (2011). Socio demographic predictors of elderly's psychological well-being in Malaysia. Aging \& mental health, 4, 437-445. http://dx.doi.org/10.1080/13607863.2010.536141

Muhamad, H., \& Jaafar, J. L. (2009). The Relation of personality to subjective well-being in Malaysian youth. International psychology bulletin, 13(1), 10-15.

Piquero, A. R., \& Weisburd, D. (2010). Handbook of quantitative criminology. New York: Springer. http://dx.doi.org/10.1007/978-0-387-77650-7

Plante, T. G., \& Sherman, C. (2001). Research on faith and health: New Approach to old questions. In T. G. Plante, \& C. Sherman (Eds.), Faith and Health: Psychological Perspectives. New York: The Guilford Press.

Rosenfield, B., \& Penrod, S. D. (2011). Research methods in forensic psychology. John Wiley \& Sons.

Wooldridge, J. M. (2012). Introductory econometrics: A modern approach (5th ed.). Cengage Learning.

World Bank. (2009). World development report 2009: Reshaping economic geography. World Bank publications, 383.

\section{Copyrights}

Copyright for this article is retained by the author(s), with first publication rights granted to the journal.

This is an open-access article distributed under the terms and conditions of the Creative Commons Attribution license (http://creativecommons.org/licenses/by/3.0/). 